\title{
DEL PENSAMIENTO FILOSÓFICO SOBRE LAS LIBERTADES A LA COACCIÓN Y CONDICIONAMIENTO DE LAS LIBERTADES Y DERECHOS POLÍTICOS: CASO VENEZUELA
}

\section{OF PHILOSOPHICAL THOUGHT ON THE FREEDOMS OF COERCION AND CONDITIONING OF FREEDOMS AND POLITICAL RIGHTS: VENEZUELA CASE
O PENSAMENTO FILOSÓFICO SOBRE A LIBERDADES À COERÇÃO E CONDICIONAMENTO DAS LIBERDADES E DIREITOS POLÍTICOS: CASO VENEZUELA}

\author{
Por: Carol Herrera
}

Doctorando del programa: La Unión Europea: problemas actuales en Derecho español y Derecho internacional" UNED. - Asamblea Nacional de Venezuela- Email: cmonserrat1@yahoo.com

\section{RESUMEN}

El catálogo de derechos sociales, civiles y políticos en Venezuela ha estado signado por la progresividad, desde las disposiciones filosóficas planteadas en el Supremo Congreso de Venezuela del año 1811. Con base en el pensamiento filosófico sobre las libertades se analizan los antecedentes de la Asamblea Nacional Constituyente de 1999 y los principios filosóficos, sociales e históricos que determinaron la "Democracia participativa y protagónica" y "Estado social de derecho y justicia" presentes en la Constitución, que bajo la premisa de derechos, la libertad, la igualdad, la propiedad, la seguridad y la justicia, permite a todos los ciudadanos, en teoría, el goce de los derechos y libertades. La Constitución vigente define al sistema democrático como "Estado social de derecho y Justicia", el cual supone como fundamento la igualdad entre los ciudadanos para ejercer sus deberes y derechos políticos. Del análisis de los elementos que integran la democracia participativa y de los derechos se concluye el advenimiento postconstitucional de un estado paralelo denominado "estado comunal" tras la promulgación de leyes orientadas a sectorizar la participación ciudadana bajo la ideología del sector oficial y el desconocimiento de los derechos humanos ante las sentencias emitidas por la Corte Interamericana de los Derechos Humanos.

Palabras claves: Supremacía constitucional, democracia participativa, libertades, derechos políticos.

JEL: K100, K190, K390. 


\section{ABSTRACT}

The catalog of social, civil, and politic rights on Venezuela it has been signed for the progressive throw the philosophical disposition raised at the Supreme Congress of Venezuela at 1811. Based on philosophical thought about the freedoms the background of Constituent National Assembly of 1999 and the philosophic, social and historic beginning which determinate "The participative and protagonist Democracy" beginning and "The rule of Law and social justice" in the Constitution, under the premise of rights, freedom, equality, property, security and justice, allows citizens, in theory, the enjoyment of their rights. The actually Constitutions defines the democratic system like "Rule of law and social" that suppose like fundament the equality between the citizens to exercise their politics duties and rights. The analysis of the elements comprising the participative democracy and the rights it conclude the advent post-constitutional of the parallel state called "Communal State" after the enacting zoning laws aimed citizens participation under the ideology of official sector and the not accepted the decision of the human rights and the judgment of the Inter-American Court of Human rights.

Keywords: Constitutional Supremacy, Rule of Law and Social Justice, Participative Democracy, Freedoms, politic rights.

JEL: K100, K190, K390.

\section{RESUMO}

O catálogo de direitos sociais, civiles e políticos em Venezuela há estado marcado por a progressividade, desde as disposições filosóficas plantadas no Supremo Congresso de Venezuela do ano 1811. Com base no pensamento filosófico sobre as liberdades analisam-se os antecedentes da Montagem Nacional Constituinte de 1999 e os princípios filosóficos, sociais e históricos que eles estabelecem os princípios da "Democracia participativa e protagónica" e "Estado social de direito e justiça" presentes na Constituição, que baixo a máxima de direitos, a liberdade, a igualdade, a propriedade, a segurança e a justiça, permite a todos os cidadãos - em teoria- o desfrutar dos direitos. A Constituição atual define o sistema democrático como "Estado social de direito e Justiça", isso supõe como fundamento a igualdade entre os cidadãos para exercer suas deveres e direitos políticos. O análise dos elementos que integram a democracia participativa e de os direitos conclui-se o advento após-constitucional de um Estado paralelo com o nome "Estado comunal" logo da promulgação das leis para fatiar a participação do cidadão na ideologia do setor oficial e a falta de direitos humanos nos acórdãos do Tribunal Interamericano de Direitos Humanos.

Palavras-chave: Supremacia constitucional, Estado de direito e da justiça social, a democracia participativa, liberdades, direitos políticos.

JEL: K100, K190, K390. 
Carol Herrera

Del pensamiento filosófico sobre las libertades a la coacción y condicionamiento

de las libertades y derechos políticos: caso Venezuela

\section{INTRODUCCIÓN}

El catálogo de derechos sociales, civiles y políticos en Venezuela ha tenido una evolución importante, signada en la progresividad, iniciada en las disposiciones filosóficas planteadas por los legisladores venezolanos en el Supremo Congreso de Venezuela del año 1811, el mismo redactó la primera Constitución Federal de los Estados de Venezuela tras la independencia de España. A lo largo de doscientos años, el constitucionalismo venezolano ha experimentado positivas transformaciones, donde los legisladores han definido los derechos que se derivan de la libertad, la igualdad, la propiedad, la seguridad y la justicia, permitiendo que los venezolanos sean incorporados plenamente como ciudadanos con derechos que les corresponde, reflejo de las influencias externas que ha recibido Venezuela de modelos constitucionales, los cuales se han adaptado para responder a las necesidades de la República, bajo el propósito de establecer un sistema garantista, que incremente la seguridad del ciudadano para desarrollar sus facultades y aptitudes sin ningún impedimento.

La transición constitucional entre las Constituciones de 1961 y 2000 no presentan grandes rupturas, al contrario, ambos textos tienen similitudes en su contenido, la Constitución de la República Bolivariana de Venezuela prevé los derechos definidos por su antecesora de manera amplia, acorde a la propuesta política y la conceptualización de democracia presentada bajo dos principios: "Democracia participativa y protagónica" la cual es sustentada por el "Estado social de derecho y justicia”, ambas nociones reconocen a la Constitución vigente no sólo como un pacto contractual gobierno-ciudadanos, sino también como un contrato de reconocimiento del ciudadano con la Sociedad Civil; no obstante cuando contrastan ambos principios en la práctica política en Venezuela, se observa como el gobierno venezolano, amparándose en las atribuciones otorgadas por la Constitución, ha creado un Estado paralelo donde el "poder popular" ha ocupado importantes espacios en la estructura gubernamental y burocrática venezolana en clara manifestación y desconocimiento de los principios constitucionales.

El presente artículo tiene por objetivo el análisis de la supremacía constitucional y principios vulnerados en la Constitución venezolana vigente, desde el catálogo de derechos civiles y políticos materializados en la Constitución de la República Bolivariana de Venezuela de 2000, los cuales son definidos bajo el concepto "Estado Social de Derecho y Justicia", con esta polisemia el constituyente de 1999 buscó establecer un amplio marco de deberes y derechos ciudadanos, reflejo de la progresividad de los derechos que surgieron de las declaraciones y proclamas derivadas del Supremo Congreso de Venezuela de 1811 con la Declaración de los Derechos del Pueblo (1 de julio) y la Carta Magna que diera vida a la República tras su independencia el 21 de diciembre de 1811.

El argumento que se trata de probar en el presente artículo son los mecanismos utilizados por el Estado venezolano al desconocer el catálogo de derechos materializados en la Constitución de la República Bolivariana de Venezuela de 2000, donde el principio "Estado social de Derecho y Justicia” es ignorado por los representantes del proyecto político actual en el país, quienes utilizan al Poder Legislativo y Judicial 
para crear estructuras análogas de Estado, denominada "poder comunal" la cual tiene por objetivo imponer el proyecto político denominado "Socialismo del siglo XXI” mediante el desconocimiento de la Constitución y adecuación de las leyes.

El concepto "Estado Social de Derecho y Justicia" ha generado distintas interpretaciones tanto a nivel constitucional como político al observarse la misma como la definición de un modelo avanzado de Estado que simétricamente coloca los derechos individuales (propiedad y libertades) al mismo nivel de los derechos colectivos (igualdad y seguridad) con lo cual se establece un sistema de corresponsabilidad retroalimentada de carácter vertical -ascendente/descendente- (Estadosociedad) con una de carácter horizontal e igualitaria (ciudadano-sociedad). Sobre esta tesis, Rojas e Ibarra (2010: 129), consideran dicho concepto como base del "Estado de bienestar" al afirmar:

(...) el desarrollo de una sociedad más civilizada y abierta. Reconoce la estructura grupal de la sociedad y la necesidad de armonizar los intereses de dichos grupos sociales, económicos, políticos y culturales, cada vez más complejos, por lo que en el ámbito social y político representa un medio para garantizar la igualdad de oportunidades y hacer efectivo el ejercicio de derechos sociales y económicos básicos.

En cambio Escarrá (2013: 80), define al concepto "Estado Social de Derecho y Justicia" como la idea central del pensamiento socialista, al considerar que el mismo responde a colocar los intereses colectivos por encima del individuo, por tanto según su percepción, el mismo se presenta como oposición a las ideas liberales siendo la base que justifica los principios del proyecto nacional denominado "Socialismo del Siglo XXI":

En tal sentido, bajo esta visión, se configura así un Estado comprometido en su existir y proceder en el desarrollo del factor social y del colectivo; enfocado y orientado a la consecución de la felicidad social, lo que implica que el mismo deba cambiar la manera de establecerse para articular todos sus medios, sus funciones, competencias y atribuciones en forjar, desarrollar y materializar ese bienestar, equilibrio y felicidad social, situación ésta que desde luego configura un rol proactivo en el mismo para la consecución de tales objetivos.

Ante ambas consideraciones opuestas sobre la definición y alcances del concepto "Estado Social de derecho y Justicia", en el presente trabajo se presenta a los orígenes del catálogo de derechos civiles y políticos, entendiendo que los mismos son el resultado de la progresividad lo largo de un milenio, los cuales sufrieron importantes transformaciones a partir del siglo XVII al XIX con los documentos surgidos de los distintos procesos revolucionarios resultando en la universalización y reconocimiento de derechos y libertades por las naciones. Igualmente se analiza como los gobiernos incurren en malinterpretaciones intencionadas de este concepto, generando el impulso de modelos políticos que tienen por objetivo desarticular la institucionalidad republicana que desconocen libertades y derechos que asisten a los ciudadanos. 


\section{ANTECEDENTES DE LA ASAMBLEA NACIONAL CONSTITUYENTE DE 1999}

\subsection{El Pacto de Punto Fijo y el impulso del sistema democrático venezolano}

El 23 de enero de 1958 Venezuela rescata la democracia tras el derrocamiento de la dictadura del General Marcos Pérez Jiménez, este suceso obligará a la redacción de una nueva Constitución la cual profundizará las libertades propuestas en la Constitución aprobada en el año 1947, permitiendo que el sistema democrático fuese inclusivo y con un alto contenido social el cual era sustentado por la renta petrolera nacional la cual impulsó el desarrollo nacional, permitiendo durante las décadas de 1960 y 1970, que el sistema democrático venezolano fuera percibido a nivel internacional como una democracia sólida y ejemplo en América Latina, que para esa época aún estaba sumergido en guerras civiles y dictaduras militares.

La base fundamental del sistema democrático venezolano se sustentó en el Pacto de Punto Fijo, acuerdo suscrito el 31 de octubre de 1958 por Rómulo Betancourt, Rafael Caldera y Jóvito Villalba, líderes de los partidos políticos Acción Democrática, Copei y URD respectivamente, bajo el beneplácito de los distintos sectores académicos, obreros, empresariales y estudiantiles del país, haciendo de este documento un pacto político y gubernativo, el cual fue adquiriendo importancia vital para la estabilidad democrática, motivado a la convocatoria de todos los sectores y fuerzas vivas de la nación, a la promoción y defensa del sistema democrático nacional, mediante la firma de un programa mínimo común donde se vieran reflejados todos estos sectores.

El mencionado Pacto estableció las bases políticas para la protección del sistema democrático, tratando de impedir que los intereses particulares de determinados partidos o agrupaciones de la sociedad civil promoviera un nuevo golpe de estado, tal y como sucedió entre los años 1945 a 1948 donde los enfrentamientos de Acción Democrática contra Copei y URD abrieron paso a la década militar (1948-1958); por tal motivo, uno de los objetivos fundamentales de la Junta de Gobierno era la convocatoria inmediata de elecciones y la redacción de una nueva Constitución, la cual garantizara los derechos ciudadanos para el goce de sus libertades.

El 23 de enero de 1961, el Congreso de Venezuela aprueba la Constitución de la República de Venezuela, esta recogerá algunos de los principios más importantes de la Constitución de los Estados Unidos de Venezuela de 1947 en lo que refiere a sistema electoral, alternancia del poder, independencia de los públicos y protección a la ciudadanía en sus derechos.

\subsection{Crisis del sistema rentista y su reflejo en la sociedad}

La historia política venezolana del siglo XX ha estado estrechamente vinculada con la economía petrolera, por ser este el principal ingreso para el sustento de los proyectos nacionales desarrollados por el gomecismo y post-gomecismo (periodo dictatorial encabezado por el general Juan Vicente Gómez, 1908-1945), trienio adeco (Constitución de 1947 correspondiente al periodo (1945-1948), la "Década Militar" sobre el Nuevo Ideal Nacional (1948-1958) y el Pacto de Punto 
Fijo (1958-1994) cuando se extingue con la llegada a la presidencia de la República de Rafael Caldera. El proyecto nacional puntofijista apoyó gran parte de sus políticas y acciones en la redistribución de las riquezas nacionales como medio para la inclusión de los sectores más deprimidos de la sociedad, integrado en su mayoría por campesinos que abandonaron los estados rurales para concentrarse en la región centro-costera venezolana con el propósito de tener acceso directo a los beneficios del ingreso petrolero.

El período de bonanza petrolera de la década de 1970 afectó positivamente a Venezuela, permitiendo que el Estado, dentro de los principios del Proyecto Político "La Gran Venezuela" estableciera una política populista de pleno empleo, donde el Estado venezolano se convirtió en el empleador mayoritario de la mano de obra calificada en Venezuela, con lo cual aumentaron los casos de corrupción y tráfico de influencias que lentamente debilitaron la legitimidad del sistema puntofijista y por ende del sistema democrático instaurado en 1958, creando una crisis económica, institucional, política y social que se reflejó en toda la década de 1980 y 1990. Sobre este particular, Lucena (2005: 59) en su trabajo La crisis política en Venezuela: repercusiones y respuestas del movimiento sindical, señala: "A partir de esta etapa -salvo en 1997, que muestra un índice realmente positivo- se evidencia una situación recesiva, que lleva ya más de veinte años, en donde los niveles de vida se han venido deteriorando".

La crisis económica iniciada en la década de 1980 generó en la población el aumento en el descontento de la población, incrementándose las protestas en demanda de mejores salarios, reducción de la inflación y mejora en los niveles de vida de los trabajadores; en el año 1983 se da la sucesión presidencial, Jaime Lusinchi candidato por Acción Democrática toma posesión como primer Magistrado de la República, iniciándose un proceso de reformas políticas diseñadas por la Comisión Presidencial para la Reforma del Estado (COPRE), la cual tenía por objetivo modernizar el programa político puntofijista, adaptándolo a las necesidades políticas, económicas y sociales que condujeran a la institucionalización de la transparencia (Combate a la corrupción y tráfico de influencias), la participación de la Sociedad Civil en el Gobierno (fortalecimiento de la democracia) y acciones conducentes a la reducción de la pobreza (Fortalecimiento del aparato productivo nacional y respeto de la propiedad privada).

Entre 1984 y 1990 la COPRE presentó diversos informes donde proponían medidas inmediatas y efectivas para el fortalecimiento del régimen constitucional de 1961 y del proyecto nacional puntofijista, aunque dichas propuestas eran positivas y ayudaban a flexibilizar la tensa situación económica, política y social en Venezuela, las mismas no fueron atendidas en su totalidad por las autoridades gubernamentales venezolanas por lo revolucionario de sus planteamientos al desconcentrar el poder, distribuyéndolo entre los actores políticos y la sociedad civil 
(Cuñarro, 2004) ${ }^{1}$; a la par la COPRE presentaba su propuestas de reformas políticas y económicas, la sociedad manifestaba su malestar mediante la protesta en reclamo de mejoras salariales, lucha contra la inflación y políticas enfocadas a atender las necesidades de los sectores más deprimidos (López; Lander: 2006) ${ }^{2}$, entre los años 1983 y 1992 en Venezuela se suscitaron más de tres mil protestas de diversos sectores del país en reclamo de mejoras y profundas reformas económicas y políticas.

A la protesta social se agrega la asimetría en las relaciones civiles-militares ocasionada por el alto grado de politización de las Fuerzas Armadas quienes desde la década de 1960 se mostraron reacios al control civil sobre la institución castrense, haciendo que a partir de la década de 1980 en cada una de las cuatro fuerzas existieran logias con distintas inclinaciones políticas que iban desde sectores conservadores (Rivero, 2010: 72-118; 172-268) ${ }^{3}$, pasando por el nacionalismo extremo hasta la izquierda radical, la unión de los sectores izquierdistas y nacionalistas fueron los que participaron en los fallidos Golpes de Estado del 4 de febrero y 27 de noviembre de 1992. El programa mínimo común preparado por los militares golpistas fue presentado ante la opinión pública como la alternativa que el pueblo reclamaba, tras su liberación en el año 1994, Hugo Chávez se presenta a las elecciones presidenciales del año 1998 bajo la bandera de la convocatoria a la Asamblea Nacional Constituyente, la cual convocó tras tomar posesión a la Presidencia de la República el 2 de febrero de 1999, de allí se ha materializado la Constitución de la República Bolivariana de Venezuela.

1. Al respecto expone: "El sistema político recibía imperiosas demandas de cambio, de su capacidad de responder a dichas exigencias dependía su mantenimiento futuro, ya que si no respondía adecuadamente, se corría peligro de que la turbulencia socio-política aumentara. Esto dependería de las capacidades del sistema político venezolano que debía abocarse a la implementación de dichas propuestas destinadas a retroalimentar su funcionamiento para lograr mantener la estabilidad política (...) También fue considerado necesario para el proceso democratizador superar la concentración del poder en manos de los principales partidos políticos, situación que exigía, que estas organizaciones fuesen reformadas estableciendo una serie de mecanismos que permitieran la expresión de las bases partidistas y la eliminación de los "enroscados".

2. En el artículo Novedades y continuidades de la protesta popular en Venezuela abarca entre el año 1983 al 2005, utilizan como fuente los datos aportados por Programa Venezolano de EducaciónAcción en Derechos Humanos (Provea) y la Base de datos El Bravo Pueblo, para efectos del presente artículo dicha estadística se toma hasta el año 1992 por ser este el año de las insurrecciones militares del 4 de febrero y 27 de noviembre, marcando una ruptura de la sociedad con el modelo de Estado propuesto desde el programa puntofijista.

3. A finales de la década de 1970 e inicios de 1980, las fuerzas armadas venezolanas estaban divididas en distintas logias que cuestionaban la legitimidad del modelo puntofijista, exigiendo reformas que combatieran la corrupción en el Gobierno y la ejecución de reformas económicas, políticas y sociales urgentes; dichos grupos se debatían entre exigir al Gobierno medidas urgentes y el desconocimiento del orden constitucional de 1961, dichos grupos se dividían en: los "Nacionalistas" -también conocida como "Logia del Samán de Güere"- liderados por el teniente coronel Hugo Chávez (ala conservadora que exigía reformas pero que a partir de 1988-1992 se convirtió en radical tras aliarse con la izquierda), los "Notables" integrado por generales y almirantes junto a intelectuales y académicos reconocidos (ala conservadora, defensora del sistema de 1961 pero que exigía reformas dentro de la supremacía constitucional) y la logia de izquierda radical liderada por el teniente coronel Francisco Arias Cárdenas (ala radical aliada a los movimientos subversivos de izquierda de la década de 1960 y 1970 quienes promovían un Golpe de Estado). En 1992 el ala nacionalista se alió con la logia de izquierda dando nacimiento al Movimiento Revolucionario Bolivariano 200 (MBR-200) iniciando los planes para el Golpe de Estado del 4 de febrero de 1992. Sobre el conflicto existente en el seno del Estado venezolano entre 1988 y 1992. 


\section{BASES FILOSÓFICAS DE LA CONSTITUCIÓN DE LA REPÚBLICA BOLIVARIANA DE VENEZUELA DE 2000}

\subsection{La supremacía constitucional de $\mathbf{2 0 0 0}$ en materia de derechos civiles y políticos, en el marco del Estado Social de Derecho y Justicia: la evolución de las libertades en Venezuela}

El catálogo de libertades expuesto en las distintas constituciones venezolanas a lo largo de doscientos años, exponen los principios de la libertad y se sustentan por el reconocimiento del Estado a los derechos inajenables e irrenunciables que poseen los ciudadanos enmarcados en la igualdad, la justicia y la propiedad; los principios fundamentales de las distintas constituciones venezolanas desarrollan las características del sistema republicano y de libertades en Venezuela, de acuerdo al contenido de la Declaración de los Derechos del Pueblo, aprobado por el Supremo Congreso de Venezuela el 1 de julio de 1811:

El triunfo del hombre sobre la naturaleza en términos político-constitucionales (...) En su parte dogmática la constitución, expresa que los gobiernos han sido creados para asegurar al hombre el bien y la felicidad, procurarle el ejercicio de sus derechos: libertad, igualdad, propiedad y seguridad... (Mijares, 2009: 415).

Dichos derechos han progresado en transcurso de la historia de la República en aras de proveer y garantizar a los ciudadanos los esquemas de deberes y derechos para el goce de sus libertades. La Constitución de la República Bolivariana de Venezuela de 2000 progresa en la garantía y reconocimiento de las libertades y la soberanía popular al otorgarle a la sociedad civil la potestad de controlar la actividad de las instituciones y promover medidas para la inclusión plena de sectores excluidos en goce pleno de sus deberes y derechos, reconociendo el derecho que poseen todos los ciudadanos al libre mercado, el uso de la propiedad privada y a ejercer sus derechos políticos libremente, todos estos principios se desarrollan desde los conceptos "democracia participativa y protagónica" y "Estado social de derecho y justicia”. La Exposición de Motivos de la Constitución de 2000 presenta las características de este modelo de Estado el cual se fundamenta en la educación y el trabajo para garantizar los fines del Estado, de manera que los ciudadanos y las organizaciones sociales promuevan la participación individual y comunitaria en el orden social y estatal, y en donde se lee "Las personas y los grupos sociales han de empeñarse en la realización y ejercicio de sus derechos y en el cumplimiento de sus deberes, mientras que el Estado es un instrumento para la satisfacción de tales fines".

El modelo constitucional social de derecho y justicia establece los postulados del Estado en el cual impulsa una serie de políticas enfocadas a satisfacer las necesidades de los sectores más deprimidos de la sociedad, sin embargo, este principio puede colisionar con los principios de libertades predefinidas, al imponerse desde el Estado una serie de políticas y leyes que excluyan a distintos sectores sociales de sus derechos a la seguridad, la propiedad y el libre comercio a fin de beneficiar a un sector de la población que reclama mayores reivindicaciones, con lo cual este modelo es complejo para la legitimación del sistema republicano moderno; sobre este particular, el jurista (Heller, 1997: 277-278) analizó: 
Toda creación de normas, es por esto y ante todo, un intento de producir mediante una normatividad creada conscientemente, una normalidad de la conducta concorde con ella. Que el experimento de la creación de normas tenga éxito en el Estado moderno, en la mayoría de los casos, a causa de su rigurosa organización burocrática, no autoriza a olvidar el hecho de que ese mismo Estado no es capaz, en manera alguna, de procurar vigencia a todas sus normas y que, aunque el experimento tenga éxito, tal éxito y, en consecuencia la vigencia que se logra, pueden presentarse en grados muy diferentes (...) Con bastante frecuencia, el uso social, la realidad social no normada extrajudicialmente, se revela más fuerte que la norma estatal.

En consecuencia las leyes son expresión de las dinámicas culturales, económicas y políticas de una sociedad determinada, donde la norma establece un marco regulatorio para las relaciones sociales entre los ciudadanos y estos con el Estado y sus instituciones garantizando la igualdad de todos los sectores del país ante las instituciones y leyes; no obstante, este principio está sometido a las peculiares interpretaciones de las autoridades a los conceptos de "equidad" y "justicia" -bases de la justicia social- con lo cual puedan favorecer a un sector de la población y desfavorecer a otros, al punto de despojarlo o desconocerle sus derechos de propiedad y libertades, pudiendo derivar que el enfrentamiento social sea inevitable, haciendo que el Estado proceda en un modelo ajeno a los principios republicanos, (Valadés, 2002: 234) afirmó: "El Estado social acaba transformando al Estado de derecho en un Estado totalitario".

En ese sentido, el constituyente venezolano de 1999, al considerar las virtudes y defectos del modelo social de derecho y justicia, estableció en la Constitución de la República Bolivariana de Venezuela una serie de principios que contuvieran las posibles arbitrariedades a las que pudiera incurrir el Estado al interpretar y aplicar la justicia social, por esa razón la supremacía constitucional venezolana de 2000 establece en el Título III de la Constitución los mecanismos por medio de los cuales la sociedad civil y los ciudadanos puedan ejecutar controles a las políticas implementadas por las instituciones del Estado venezolano.

La aplicación efectiva de los principios de control ciudadano plasmado en la Constitución de la República Bolivariana de Venezuela de 2000, exige que la ciudadanía tenga pleno conocimiento de sus deberes y derechos, además de la comprensión del texto constitucional no es solo un acto de reconocimiento verticaldescendente (Gobierno-ciudadano), sino también de carácter horizontal-igualitario (ciudadano-cuerpo social), pues, la garantía constitucional al proteger al débil no sólo se refiere a garantizar los derechos ciudadanos ante las arbitrariedades del Estado, sino también proteger al ciudadano de los abusos en que pudiera incurrir la sociedad al desconocer o quebrantarle sus derechos.

\subsection{Propuesta de un modelo democrático participativo y protagónico}

La Constitución de la República Bolivariana de Venezuela (2000), tiene dos características importantes: la primera pretende el fortalecimiento del sistema federal descentralizado; la segunda es la incorporación de las propuestas de la COPRE integrando el contenido de la Constitución, ambos elementos pues, definen 
al texto constitucional como garantista, no sólo en lo que refiere al fortalecimiento de los poderes regionales (consejos legislativos estadales, consejos municipales y juntas parroquiales), sino que también establece y define los deberes y derechos que asisten a la sociedad civil, máxima expresión del Poder Constituyente, el cual tendría definida su participación en la actividad pública y política nacional a través de las asambleas de ciudadanos y los mecanismos de consulta (referendos, asambleas de ciudadanos, cabildos); la Exposición de Motivos de la Constitución de la República Bolivariana de Venezuela orienta la participación de los ciudadanos a la intervención "del pueblo en los procesos de formación, formulación y ejecución de las políticas públicas", aspira el constituyente superar las deficiencias de gobernabilidad, experimentadas por largos periodos en la política venezolana, separada del Estado y la sociedad.

El carácter que adquiere la Sociedad Civil en la Constitución, conceptualiza la descentralización del poder como el reconocimiento que dan las instituciones republicanas a la sociedad civil en su carácter de contralor y depositario absoluto de la soberanía nacional, estableciendo como principio constitucional la transparencia y la gobernanza, donde el ciudadano y la sociedad civil tienen la facultad de intervenir directa (asamblea de ciudadanos, cabildos o referéndum popular) e indirecta (Asamblea Nacional y Consejos Legislativos estadales) en los asuntos nacionales y definir las políticas públicas. El Capítulo IV "De los derechos políticos y del referéndum popular" contenido en el Título III "De los derechos humanos y garantía de los deberes" está constituido entre los artículos 62 al 74, definiendo la participación directa e indirecta de la sociedad civil, sobre este particular, consta en el Diario de Debate (1999) durante el discusión de este artículo en la Asamblea Nacional Constituyente de 1999, la participación del constituyente, en la sesión del 24 de octubre donde sustentó los principios de la "Democracia participativa y protagónica" al exponer:

La democracia participativa se da no solamente con el voto, se da también en el debate sobre las decisiones cualitativas del Estado nacional que puede ser sobre todo el problema del comportamiento económico de una Nación, como se puede dar también a nivel regional, a nivel municipal, a nivel de una parroquia (Díaz, 1999).

Ahora bien, vistos los planteamientos desarrollados en la cita anterior es pertinente analizar los elementos que integran la democracia participativa y protagónica expuesta en la Constitución de la República Bolivariana de Venezuela bajo dos interrogantes: ¿La democracia participativa y protagónica significa la aniquilación de los cuerpos colegiados electos por votación popular? O más bien ¿Es un principio que fortalece los principios del sistema republicano liberal surgido en el siglo XVIII? La respuesta es simple, la democracia participativa y protagónica no es más que la progresividad del modelo democrático representativo el cual se sustenta en el ejercicio de soberanía que ejercen los ciudadanos donde la sociedad civil adquiere relevancia en el control de la gestión pública y ejercicio de los poderes públicos e instituciones del Estado. 


\section{DES-DESINTEGRACIÓN DE LA SUPREMACÍA CONSTITUCIONAL}

La Constitución de la República Bolivariana de Venezuela es garantista, en teoría el Estado y los distintos sectores de la sociedad civil cooperan para proteger los derechos ciudadanos y el cumplimiento de las leyes, cuyos principios están subordinados a la supremacía constitucional que establece los mecanismos de equilibrio e independencia de los poderes públicos nacionales en función de garantizar y proteger los derechos ciudadanos, estando la misma acorde a la universalización de los derechos humanos, a los derechos políticos. No obstante se agregan las acciones ejecutadas por el Estado venezolano a partir del año 2007 en crear una estructura paraestatal denominada "poder popular", la misma es creada por una interpretación conducida del concepto soberanía popular a la cual definen como "estado comunal" teniendo por objetivo desplazar lentamente la supremacía constitucional, base de la institucionalidad republicana.

\subsection{La progresiva reversión de los derechos humanos en Venezuela}

En materia de derechos humanos la Constitución de 2000 garantiza la progresividad de los mismos, ello se refleja en los artículos 2, 3, 19, 23, 25, 26, 29, 30, 31 y 55 donde la supremacía constitucional obliga al Estado y sus instituciones garantizar y promover el reconocimiento de los derechos humanos, no sólo en lo que refiere a protegerlo de las arbitrariedades en la que puedan incurrir las autoridades, sino también en los abusos del que pueda ser víctima el ciudadano ante el cuerpo social en su conjunto; en relación a dichos temas, se destacan los artículos 23, 30 y 31 de la Constitución de 2000, al establecer las funciones del Estado en el reconocimiento y protección de los derechos humanos tanto de la sociedad como del individuo. La superioridad de los tratados, pactos y convenciones relativos a derechos humanos, suscritos y ratificados por Venezuela, sobre el orden interno, en la medida en que contengan normas sobre su goce y ejercicio más favorables a las establecidas en esta Constitución y en las leyes de la República, y son de aplicación inmediata y directa por los tribunales y demás órganos del Poder Público, previsto en el artículo 3 constitucional, el cual fue posteriormente interpretado por la Sala Constitucional del Tribunal Supremo de Justicia en sentencia, negando la aplicación inmediata de los derechos previstos en tratados y compromisos internacionales.

Por otra parte, el artículo 31 constitucional consagra el derecho a los ciudadanos a dirigir peticiones o quejas ante los órganos internacionales; quedando el Estado en la obligación de adoptar las medidas para cumplir con las decisiones emanadas de los órganos internacionales con los cuales el Estado mantenga compromisos adquiridos.

Luego del Golpe de Estado del 11 de abril de 2002 y la vuelta a la institucionalidad al país pasadas las 48 horas, el Poder Ejecutivo comenzó un lento proceso de control de las instituciones, vulnerando la independencia de los Poderes Públicos. Aunque el proceso de control del Poder Judicial inició en el año 1999 tras la instalación de la Asamblea Nacional Constituyente, la cual en el marco del proceso de reestructuración de los poderes públicos derivados de la Constitución de 1961, aprobó el 19 de agosto de 1999 la "reorganización del poder judicial” mediante 
decreto (Decreto de Reorganización del Poder Judicial, 1999); ; el mismo ordenaba, la intervención de la Corte Suprema de Justicia, Consejo de la Judicatura y todos los tribunales, la cual sería realizada por la Comisión de Emergencia Judicial, la cual tendría facultades extraordinarias en lo que refiere a la supervisión del sistema judicial de la República así como en la destitución de jueces y magistrados que incurran en faltas graves o no respondan a los requerimientos de la reorganización judicial propuesta por la Asamblea Nacional Constituyente.

$\mathrm{Al}$ entrar en vigencia la Constitución de la República Bolivariana de Venezuela, el tema judicial continuaba sin resolverse, las disposiciones planteadas en el Decreto de Emergencia Judicial no se cumplieron, ocasionando que la transición hacia un sistema judicial eficiente y apegado al imperio de la ley y al Estado de Derecho permaneciera en una eterna transición, donde la mayoría parlamentaria adepta al oficialismo ha promulgado distintas leyes para mantener el control y designar a los magistrados del Tribunal Supremo de Justicia y jueces (Harting, 2006: 23-76).

Sobre este particular se destaca en la destitución de los jueces de la Corte Primera de lo Contencioso Administrativa Ana María Ruggeri Cova, Perkins Rocha Contreras y Juan Carlos Apitz (Informe No 24/05, 2005), mediante decisión de la Comisión de Funcionamiento y Reestructuración del Sistema Judicial realizada el 30 de octubre de 2003, se aprobó en razón que dichos jueces incurrieron en "grave error judicial inexcusable"5, es importante resaltar que dicha corte había dictado sentencias en contra del Estado venezolano en temas que ocupaban la opinión pública nacional $^{6}$.

4. El "Decreto de Reorganización del Poder Judicial", aprobado el 19 de agosto de 1999, publicado en la Gaceta Oficial N 36.782 del 8 de septiembre de 1999, establece las funciones supraconstitucionales que tendría la Comisión de Emergencia Judicial las cuales quedarían establecidas en los artículos 3, 4 y 5 (Funciones de control sobre las instituciones del sistema judicial del país y subordinación de los jueces y magistrados a la misma), artículos 6, 7, 8 y 9 (evaluación y suspensión de jueces que señalados por casos de corrupción o retardo en dictar sentencias, procediéndose a su suspensión o remoción inmediata) y los artículos 12 al 24 (proceso de evaluación, concurso y selección de nuevos jueces).

5. Sentencia dictada por la Comisión de Funcionamiento y Reestructuración del Sistema Judicial (Doctores: Juan Carlos Apitz Barrera, Perkins Rocha Contreras, Luisa Estella Morales Lamuño, Ana María Ruggeri y Evelyn Marrero Ortiz). Caracas, del 30 de octubre de 2003, ponente: Dr. Beltrán Haddad. Expediente $\mathrm{N}^{\circ}$ 1052-2003. Publicado en la Gaceta Oficial de la República Bolivariana de Venezuela $\mathrm{N}^{\circ} 37.810$ del martes 4 de noviembre de 2003. El fallo de la Comisión de Funcionamiento y Reestructuración del Sistema Judicial fue realizado tras el fallo de la Sala Político Administrativa del Tribunal Supremo de Justicia (Expediente 202-898 del 3 de junio de 2003) en relación a la solicitud de avocamiento de la ciudadana Jenny Mariela Lugo Méndez, ordenando a la Corte Primera de lo Contencioso Administrativo continuar los procesos respectivos. Posteriormente, el 12 de septiembre de 2003 el Inspector General de Tribunales acusó a los magistrados de dicha corte de haber incurrido en "errores inexcusables", pasando el caso a la Comisión de Funcionamiento y Reestructuración del Sistema Judicial que dictó la destitución de los referidos magistrados.

6. Entre los fallos dictados por la Corte Primera de lo Contencioso Administrativo se encuentran: Suspensión de los Consejos de Investigación contra los militares que participaron en los sucesos del 11 de abril de 2002 o sospechosos de haber participado, medidas en contra de la intervención de la Policía Metropolitana de Caracas por efectivos militares, medidas cautelares a favor de los trabajadores petroleros acusados de haber participado en el paro nacional de los años 2002-2003 y medidas en contra de la presencia de médicos cubanos en la Misión Barrio Adentro. Véase: Comisión Interamericana de Derechos Humanos, Informe No 24/05. Petición 282/04: Admisibilidad Ana María Ruggeri Cova, Perkins Rocha Contreras y Juan Carlos Apitz Barbera. 8 de marzo de 2005. 
Los fallos en contra de magistrados de Corte Primera de lo Contencioso Administrativo fueron apelados ante la Corte Interamericana de Derechos Humanos y el Comité de Derechos Humanos de Naciones Unidas, en ambos casos el Estado venezolano, tanto a nivel del Tribunal Supremo de Justicia, Ministerio Público, Defensoría del Pueblo y Presidencia de la República han manifestado su rechazo a dichas opiniones por considerar que dichos representantes "interfieren" en la soberanía venezolana, cuando la Constitución de 2000 establece en los artículos 23 y 31 el derecho que tienen los ciudadanos a asistir a los tribunales y organismos internacionales a fin de apelar un fallo judicial o solicitar medidas de protección, estando el Estado venezolano en la obligación de respetar y cumplir los fallos dictados por estas instancias.

En lo que refiere a los magistrados de la Corte Primera de lo Contencioso Administrativo, la Corte Interamericana de Derechos Humanos el 5 de agosto de 2008 dictó sentencia a favor de los ciudadanos Ana María Ruggeri Cova, Perkins Rocha Contreras y Juan Carlos Apitz, ordenando al Poder Judicial venezolano restituirlo en sus funciones en dicho tribunal, pago de indemnización, así como la aprobación del Código de Ética del Juez y Jueza venezolano; la reacción del Estado venezolano se materializó mediante la Sentencia N 1939, del (Recurso de Interpretación, 2008) dictado por la Sala Constitucional del Tribunal Supremo de Justicia, expediente $\mathrm{N}^{\circ}$ 08-1572, la cual analizó la sentencia del 5 de agosto de 2008 mediante el estudio del artículo 23 constitucional, estableciendo en dicha sentencia, que la misma atenta en contra de la soberanía venezolana, recomendando al Estado venezolano la denuncia de la Convención Americana sobre Derechos Humanos con lo cual la República Bolivariana de Venezuela abandona la CIDH, desconociendo el fallo en su contra. Dicha sentencia sostiene que la aplicación de la misma (...) afectaría principios y valores esenciales del orden constitucional de la República Bolivariana de Venezuela y pudiera conllevar a un caos institucional en el marco del sistema de justicia, al pretender modificar la autonomía del Poder Judicial constitucionalmente previsto y el sistema disciplinario instaurado legislativamente (...).

La supremacía constitucional de 2000 si bien se presenta como una de las más avanzadas del mundo en lo referente al reconocimiento y adaptación a la normativa internacional en materia de Derechos Humanos, en la práctica ha estado vulnerada mediante prácticas ilegítimas de la Sala Constitucional del Tribunal Supremo de Justicia, atendiendo a parcialidad política, dejando en evidencia el quebrantamiento de la independencia e institucionalidad de los poderes públicos, a fin de lograr imponer los objetivos del proceso político, siendo una muestra de ello el desconocimiento de las sentencias de la Corte Interamericana de los Derechos humanos y la posterior denuncia por parte del Estado venezolano a la Convención Interamericana, conduciendo al país a un retroceso importante de los principios de libertad, justicia, igualdad, seguridad, bases del sistema constitucional venezolano desde 1811 hasta nuestros días, haciendo que el Poder Ejecutivo a través del sistema paraestatal promueva el desconocimiento de los derechos políticos y por ende, la vulneración de los derechos ciudadanos en lo que refiere a la seguridad jurídica, desconociendo las medidas que amparan a los ciudadanos desde las instancias internacionales. 


\subsection{Poder Popular y Estado Comunal: el Estado de Derecho y ¿La Institucionalidad Constitucional de 2000?}

La supremacía constitucional de 2000 entre sus principios define la reducción del papel absoluto del Estado en las actividades gubernamentales, las cuales son reguladas mediante la interrelación Estado - Sociedad Civil a fin de impulsar y garantizar no sólo la transparencia en la gestión pública, sino también en el ejercicio de una democracia más directa, donde el cuerpo social defina y establezca las políticas para la asignación de recursos, gestión pública, gobernabilidad y garantía de la subordinación militar al poder civil, todos estos aspectos constituyen las características de la "Gobernanza", la cual es el desplazamiento de la burocracia convencional por un sistema de administración cooperativo, donde el Estado y los distintos sectores que conforman la Sociedad Civil definen las políticas públicas, garantizando una amplificación del sistema democrático (Mayntz, 2011), aunado al acercamiento Poder Público-Sociedad Civil, estos principios se materializan en la Constitución de la República Bolivariana de Venezuela en el Título II "De los derechos humanos, garantías y los deberes”, artículos 19, 20, 22, 25, 51, 52, 53, 55, 57, 62, 67, 68 y 70, necesario es desarrollar en condiciones de igual el contenido constitucional sobre las libertades y deberes contemplados en él.

En lo que refiere a las características, atribuciones y alcances de la Sociedad Civil, diversos autores han expresado sus impresiones sobre este tema, Maquiavelo (El Príncipe, 1513), Hobbes (Leviatán, 1651) y Locke (Tratados sobre el Gobierno Civil, 1680) definen a la Sociedad Civil como la unión de todos los individuos que conforman el cuerpo social a fin de proteger los intereses tanto individuales como colectivos, cuya asociación es de carácter involuntaria a fin de garantizar su permanencia y defensa de sus derechos tanto individuales como colectivos, los cuales son regulados o dirigidos por una autoridad a la cual están asociadas la cual puede recaer en un individuo o en varios designados por los integrantes de dicho cuerpo social; posteriormente en el período previo de las Revolución Americana (1776) y Revolución Francesa (1789), la Sociedad Civil adquiriría nuevas características, donde autores como Montesquieu (El Espíritu de las Leyes, 1748), Jean-Jacques Rousseau (Discurso sobre el origen y los fundamentos de la desigualdad entre los hombres, 1755; El Contrato Social, 1762) y Thomas Paine (Sentido Común, 1776; Los Derechos del Hombre, 1791) materializarían una nueva característica de la Sociedad Civil, a la cual se le endosaba todo principio de soberanía del Estado, tal y como lo expusiera Emmanuel-Joseph Sieyès en su obra ¿Qué es el Tercer Estado?:

Los derechos políticos, del mismo modo que los derechos civiles, deben vincularse a la cualidad de ciudadano. Esta propiedad legal es idéntica para todos, sin distinción alguna derivada de la mayor o menor propiedad real de que goza cada individuo. Todo ciudadano que reúne las condiciones fijadas para ser elector tiene derecho a hacerse representar y su representación no puede ser una fracción de la representación de otro. Este derecho es uno y todos han de ejercerlo igualmente, del mismo modo que todos se hallan igualmente protegidos por la ley que han concurrido a hacer (Sieyès, 1789: 24). 
Las propuestas desarrolladas por los citados autores forman la base sobre la cual se desarrollaron las principales declaraciones de derechos que sustentan los procesos revolucionarios e independentistas durante los siglos XVIII y XIX, allí se reconocía al Pueblo como depositario absoluto de soberanía, principal característica del republicanismo moderno. En el caso venezolano, los principios fundamentales que ha sustentado el sistema constitucional han estado determinados por la Declaración de los Derechos del Pueblo de 1811, redactado por Juan Germán Roscio y aprobado por el Supremo Congreso de Venezuela el 1 de julio de 1811, estableciendo en su preámbulo el espíritu de este documento:

\begin{abstract}
El Supremo Congreso de Venezuela en su sesión legislativa, establecida para la provincia de Caracas, ha creído que el olvido y el desprecio de los Derechos del Pueblo, ha sido hasta ahora la causa de los males que ha sufrido por tres siglos: y queriendo empezar a precaverlos radicalmente, ha resuelto, conformándose con la voluntad general, declarar, como declara solemnemente ante el universo, todos estos mismos derechos inajenables, a fin de que todos los ciudadanos puedan comparar continuamente los actos del Gobierno con los fines de la institución social: que el magistrado no pierda jamás de vista la norma de su conducta y el legislador no confunda, en ningún caso, el objeto de su misión (Brewer-Carias, 2011: 121).
\end{abstract}

La Declaración de los Derechos del Pueblo de 1811 establece los principios del sistema republicano del cual derivarán las distintas constituciones venezolanas, las cuales al definir sus disposiciones fundamentales, establecen a Venezuela como un Estado democrático, republicano sustentada por la soberanía popular, la cual tiene una serie de derechos irrenunciables como son: la libertad, la justicia, la propiedad, la seguridad y la igualdad, los cuales han progresado a lo largo de doscientos años en los distintos textos constitucionales. La Constitución de la República Bolivariana de Venezuela de 2000, reconoce estos derechos aunadas a las distintas declaraciones internacionales, pactos, convenciones y protocolos en materia de derechos humanos, manifiesta la supremacía constitucional venezolana de 2000, donde la Sociedad Civil adquiere deberes y derechos que definen su participación en la actividad política nacional junto a los poderes constituidos en el marco de la Democracia Participativa y Protagónica.

En el año 2006 la postura política del líder del gobierno define su proyecto político como "socialismo bolivariano", abocado a un "poder popular" convocado para ejercer el poder por medio de las comunas; en la presentación del proyecto de reforma a la Constitución, el presidente expuso ante la Asamblea Nacional el 15 de agosto de 2015, las características de ese Poder Comunal, la cual sería financiada por el Estado.

La propuesta de reforma constitucional presentada por el presidente de la República fue rechazada en referéndum popular el 2 de diciembre del año 2007, sin embargo, el Gobierno Nacional en los años 2009 y 2010 impuso las diversas propuestas de reforma por otras vías, entre ellas se encuentra el tema del estado 
comunal, sistema mediante el cual se pretendía establecer una forma administrativa y territorial paralela al Poder Público, al sistema convencional materializado en las gobernaciones y alcaldías, donde la comuna tendría recursos propios y autoridad. Entre los años 2009 al 2010 la mayoría oficialista de la Asamblea Nacional aprobó la serie de leyes denominada "Leyes del Poder Popular" las cuales se distribuyen en: Ley Orgánica de Contraloría Social, Ley Orgánica de las Comunas, Ley Orgánica de los Consejos Comunales, Ley Orgánica del Poder Popular, Ley de Planificación Pública y Popular y Ley Orgánica del Sistema Económico Comunal. En la Ley del Poder Popular se define a este en el artículo 8 como:

Forma de organización político social, fundada en el Estado democrático y social de derecho y de justicia establecido en la Constitución de la República, en la cual el poder es ejercido directamente por el pueblo, con un modelo económico de propiedad social y de desarrollo endógeno sustentable, que permita alcanzar la suprema felicidad social de los venezolanos y venezolanas en la sociedad socialista. La célula fundamental de conformación del estado comunal es la Comuna (Ley del poder popular, 2010).

Estableciendo los fines del Poder Popular, comunes en dichas leyes. En lo que refiere al tema económico, en especial el artículo 6, numerales 3, 10, 12 y 14 de la Ley Orgánica del Sistema Económico Comunal la cual desconoce el principio de propiedad privada, impone el sistema de trueque (desconocimiento del libre mercado y empresa) e impone un sistema de producción y comercialización el cual será dominado por las instancias comunales de acuerdo a lo que dicte el gobierno Nacional, contrario al contenido de los artículos 112 y 115 de la Constitución de la República Bolivariana de Venezuela, las cuales reconocen el derecho que tienen los ciudadanos a ejercer libremente la actividad económica de su preferencia siendo la misma defendida y garantizada por el Estado (libertad de comercio y libre empresa) artículo 112 constitucional venezolano, así como el reconocimiento y obligación que tiene el Estado de promover y respetar la propiedad privada en lo que refiere al uso de las mismas, las cuales estarán reguladas por las leyes para su ejecución y garantía, artículo 115 constitucional; en lo que refiere a la promoción y protección de las industrias populares ellas quedan protegidas y garantizadas en el artículo 309 constitucional, sin que ellas interfieran o menoscaben el derecho que poseen los ciudadanos en lo que refiere a la libre empresa, así como en la adquisición y disfrute de la propiedad privada.

En lo que refiere a los mecanismos de participación ciudadana las leyes del poder popular reconoce la asamblea de ciudadanos como medio para generar la autogestión de las comunidades, sin embargo, estos principios son limitados pues las mismas deben responder al postulado de "socialismo" definido por dichas leyes con lo cual el Estado enajena en dichas leyes el legítimo derecho que posee la sociedad civil para definir las políticas en sus comunidades en concordancia con las instancias de poder definidas en la Constitución como son las alcaldías y gobernaciones, entre los cuales se encuentran el artículo 2 de la Ley Orgánica de los Consejos Comunales; numeral $5^{\circ}$ del artículo 5 de la Ley Orgánica de Contraloría 
Social; artículo 5 de la Ley Orgánica de las Comunas; artículo 5 y numeral $1^{\circ}$ del artículo 7 de la Ley Orgánica del Poder Popular; artículo 3 de la Ley Orgánica de Participación Popular y numeral $4^{\circ}$ del artículo 4 de la Ley Orgánica del sistema Económico Comunal, estructurando mediante leyes un sistema análogo a los principios establecidos en la Constitución venezolana de 2000 al imponer mediante leyes el modelo socialista.

Los conceptos "Estado social de Derecho y justicia”, "Democracia participativa”, protagónica” y "Justicia social”, conjunto de principios establecidos y definidos en la Constitución de la República Bolivariana de Venezuela de 2000, son tergiversados intencionalmente por los promotores del proyecto político al exponer que los mismos son bases del Estado Socialista, justificando con ello el desconocimiento de los principios jurídicos y filosóficos que definen los derechos que asisten a la ciudadanía como son la propiedad, la libertad, la justicia y la igualdad, los cuales son sustituidos por un régimen que legitima la colectivización de la propiedad y por tanto la implementación de un pensamiento único, destinado a desarticular la institucionalidad republicana, y por ende, el Estado de derecho expuesto en el texto constitucional de 2000.

\section{CONSIDERACIONES FINALES}

El catálogo de derechos y libertades plasmado en la Constitución de la República Bolivariana de Venezuela de 2000 es avanzado al reconocer los tratados que sobre esta materia se han suscrito en los distintos organismos internacionales, permitiendo que los mismos sean progresivos donde la acción mancomunada Estado-sociedad civil garanticen el Estado de derecho propuesto en la supremacía constitucional de 2000; sin embargo, en la práctica el proyecto nacional chavista presentado en el I Plan Socialista de la Nación 2007-2013 -Proyecto Nacional Simón Bolívar- ha limitado el esquema de libertades presentados en la Constitución al generar un sistema análogo dominado por el estado comunal, el cual está subordinado a las directrices del Poder Ejecutivo Nacional, desde donde se imponen las leyes del poder popular y sus reglamentos los cuales contravienen los derechos que poseen los ciudadanos a la igualdad, la libertad y la propiedad, cercenando además las acciones de contraloría que intenta aplicar la sociedad civil.

Las acciones del Gobierno venezolano al desconocer el contenido de la Constitución de la República, generarán una serie de conflictos que amenazan a la estabilidad de la Nación que derivará en la deslegitimación del texto constitucional y sus instituciones, con lo cual el marco legal de la República se ve suplantado por una serie de leyes justificadas mediante las sentencias de la Sala Constitucional del Tribunal Supremo de Justicia, lo cual permite en la actualidad coexistir dos sistemas el que estableció en la Constitución de la República de 2000 el Estado Social de Derecho y de Justicia, mediante un gobierno democrático, participativo, pluralista y el prescrito desde 2009 aprobación de la Ley de Consejos Comunales y posteriormente en diciembre de 2010 en las nuevas leyes que conforman el nuevo "estado social comunal" mediante el poder popular. 
El modelo de Estado propuesto por el gobierno venezolano en el I Plan Socialista de la Nación y el Plan de la Patria -II Plan Socialista- están determinadas a someter a Venezuela a un modelo distinto al previsto en la Constitución venezolana, el modelo descrito en ambos planes procuran una participación popular condicionada a los consejos comunales, registrados en entes dependientes del Ejecutivo Nacional limitando los derechos políticos de los ciudadanos no afectos al partido de gobierno ni a su ideología política.

El Poder Ejecutivo se ampara en la Constitución, leyes e instituciones para imponer a la sociedad un modelo político único, desconociendo las libertades y los derechos de participación de la sociedad civil, al someter a los ciudadanos a los rigores de un Estado que mediante leyes solo reconoce la participación ciudadana de los partidarios políticos al procurar la legislación orientadas a un estado comunal socialista, desconociendo la pluralidad política, vulnerando las libertades más elementales, excluyendo a la República del sistema jurisdiccional interamericano sobre los derechos humanos, impidiendo a los ciudadanos actuar ante dicho organismo. El desconocimiento de los derechos políticos como derechos humanos previstos en la Constitución limita, coacciona las libertades elementales de los ciudadanos. 


\section{REFERENCIAS}

1. BREWER-CARÍAS, Allan (2011). Las declaraciones de los derechos del pueblo y del hombre de 1811. Academia de Ciencias Políticas y Sociales - Fundación Juan Germán Roscio, Caracas, Venezuela. Pp. 223.

2. CONSTITUCIÓN DE LA REPÚBLICA BOLIVARIANA DE VENEZUELA (2009). Enmienda, Gaceta Oficial de la República Bolivariana de Venezuela № 5.908 (Extraordinaria), 19 febrero. Gaceta Oficial de la República Bolivariana de Venezuela №5.453 (Extraordinaria), 24 de marzo 2000.

3. CUÑARRO C., Edith (2004). Venezuela 1984-1999: 15 años de historia (La Comisión Presidencial para la Reforma del Estado (COPRE) como mecanismo de innovación política. Revista Cuestiones políticas Volumen 20, Núm. 33. Facultad de Ciencias Jurídicas y Políticas de la Universidad del Zulia. [En línea] Disponible en: http:// www.produccioncientifica.luz.edu.ve/index.php/cuestiones/article/view/14388 (consultado mar. 10- 2015).

4. DECRETO DE REORGANIZACIÓN DEL PODER JUDICIAL (1999). Gaceta Oficial de la República Bolivariana de Venezuela $\mathrm{N}^{\circ}$ 36.782, 8 de septiembre de 1999.

5. DÍAZ, Daniel (1999). Diario de Debates, Asamblea Nacional Constituyente de Venezuela. (Edición digital), sesiones, 24 de octubre de 1999.

6. ESCARRÁ M., Carlos. Consideraciones libres sobre el Socialismo Bolivariano (2013). Escuela de Formación Integral de la Asamblea Nacional “Dr. Carlos Escarrá Malavé". Asamblea Nacional de la República Bolivariana de Venezuela (2013, segunda edición). Caracas, Venezuela. Pp. 80-161.

7. EXPOSICIÓN DE MOTIVOS DE LA CONSTITUCIÓN DE LA REPÚBLICA BOLIVARIANA DE VENEZUELA [En línea]: Disponible en http://www.mp.gob.ve/LEYES/constitucion/constitucion1.html (consultado mar. 19-15).

8. HARTING V., Iván (2006). Naturaleza jurídica del procedimiento disciplinario contra jueces. Trabajo de Grado para optar al título de especialista en Derecho Procesal. Universidad Católica Andrés Bello, Caracas, Venezuela. Pp. 181.

9. HELLER, Hermann (1977). Teoría del Estado, Fondo de Cultura Económica, Ciudad de México, México. Octava reimpresión. Pp. 328.

10. INFORME № 24/05. Petición 282/04: Admisibilidad Ana María Ruggeri Cova, Perkins Rocha Contreras y Juan Carlos Apitz Barbera. 8 de marzo de 2005. Corte Interamericana de los Derechos Humanos [En línea]: Disponible en: https://www.cidh.oas.org/annualrep/2005sp/Venezuela282.04sp.htm\#_ftn3 (consultado mayo. 12-15).

11. LEY ORGÁNICA DEL PODER POPULAR, Ley Orgánica de Planificación Pública y Popular, Ley Orgánica de las Comunas, Ley Orgánica del Sistema Económico Comunal y Ley Orgánica de Contraloría Social. (2010) Gaceta Oficial de la República Bolivariana de Venezuela Nº 6.011 (Extraordinaria), 21 de diciembre. PG.

12. LÓPEZ M., Margarita; LANDER, L., (2006) Novedades y continuidades de la protesta popular en Venezuela. Revista Venezolana de Economía y Ciencias Sociales, Vol. 12 Núm. 1, Caracas enero-abril.

13. LUCENA, Héctor, La crisis política en Venezuela: repercusiones y respuestas del movimiento sindical (2005). Sindicatos y nuevos movimientos sociales en América Latina Pp. 59 [En línea] Disponible en http://biblioteca. clacso.edu.ar/clacso/gt/20101109025145/3lucena.pdf (consultado mayo. 10- 2015). en: http://www.ucv. ve/fileadmin/user_upload/faces/problemas_sociales_contemporaneos/CESOC/ENERO_ABRIL_1_2006_ LA_NACIONALIZACION_PETROLERA_EN_VENEZUELA.pdf. (Consultado mayo. 10-15). 
14. MAYNTZ, Renate (2011). El Estado y la sociedad civil en la gobernanza moderna. Revista Reforma y democracia Centro Latinoamericano de Administración para el Desarrollo (CLAD), Núm. 21, octubre 2011. Documento en línea:http://pubman.mpdl.mpg.de/pubman/item/escidoc:1234838/component/escidoc:2060890/ RD_21_2001_Mayntz.pdf (consultado may. 18-15).

15. MIJARES, Víctor (2009). Constitución - Venezuela. En: FERNÁNDEZ SEBASTÍAN, Javier (Director) Diccionario político social del mundo Iberoamericano. Centro de Estudios Políticos y Constitucionales. Madrid, España. Pp. 415-417.

16. RECURSO DE INTERPRETACIÓN DE LA SALA CONSTITUCIONAL, TRIBUNAL SUPREMO DE JUSTICIA (2008). Expediente $N^{\circ}$ 08-1572. Admisibilidad del fallo de la Corte Interamericana de Derechos Humanos contra el Estado venezolano del 5 de agosto de 2008. Caracas, 18 de diciembre de 2008 (Edición digital) En: Tribunal Supremo de Justicia de la República Bolivariana de Venezuela, biblioteca [En línea] Disponible en: http:// historico.tsj.gob.ve/decisiones/scon/diciembre/1939-181208-2008-08-1572.HTML (consultado abr. 17-15).

17. RIVERO, Mirtha (2010). La rebelión de los náufragos, Alfa, Caracas, Venezuela, nov. 2010 (primera reimpresión) Pp. 461.

18. ROJAS María; IBARRA Francisco (2010). La justicia y los derechos sociales. En: GERALDES DA CUNHA L., Teresa M. (Coordinadora). Derechos, Libertades y Sociedad de la Información. Facultad de Derecho y Ciencias Sociales de la Universidad Michoacana de San Nicolás de Hidalgo. Pp. 129.

19. VALADÉS, Diego (2002). La no aplicación de las normas y el Estado de Derecho. Boletín Mexicano de Derecho Comparado, Vol. XXXV, Núm. 103, enero-abril. [En línea]: Disponible en: http://info.juridicas.unam.mx/ publica/rev/boletin/cont/103/art/art8.htm (consultado abr. 20-15). PG

20. SIEYÈS, Emmanuel-Joseph (1789). ¿Qué es el Tercer Estado? Edición digital, publicado por Dr. Boris González, página electrónica [En línea]: Disponible en: https://borisbarriosgonzalez.files.wordpress.com/2011/09/ sieyes-que-es-el-tercer-estado.pdf (consultado abr. 18-15). 


\title{
RENÉ BÁEZ: ENTRE LA LETRA, LA SANGRE Y LA UTOPÍA
}

\author{
Teresinka Pereira
}

\begin{abstract}
(ALAl: 30/09/2015) http://www.alainet.org/es/articulo/172731
See more at: http://www.alainet.org/es/articulo/172731\#sthash.VNY7h8Da.dpuf

Entrevista de Teresinka Pereira, presidenta de la International Writers Association, al economista y escritor ecuatoriano René Báez- Integrante del Comité Científico de la Revista Tendencias
\end{abstract}

\section{¿Cómo ha sido tu educación y cómo llegaste a ser Decano de una universidad católica?}

Me siento producto tanto de una educación formal confesional-católica como del modelo racionalista y laico que implantara en Ecuador la Revolución liberal de 1895. Después de las ardorosas e incluso cruentas confrontaciones entre conservadores y liberales a lo largo del siglo XIX, el país se beneficiaría de la coexistencia pacífica de dos vertientes formativas de inspiración humanista.

Lo anterior explicaría que, en mi caso, la carrera de docente e investigador la pudiera desplegar sin obstáculos institucionales durante más de tres décadas de vinculación laboral tanto a la estatal Universidad Central como a la privada Pontificia Universidad Católica de Quito. Lamentablemente, este diagrama de la educación que prevaleciera largamente en Ecuador -igual en América Latina- está siendo radicalmente subvertido en el país por las reformas en ese sector instrumentadas por el régimen de Rafael Correa, en tributo a postulados y valores/antivalores de raigambre darwiniana, etiquetados como la educación por competencias.

Con sobra de razones a este peregrino paradigma educacional, mentalizado por la Organización Mundial del Comercio (OMC), se le ha venido cuestionando por constituir un elemento vertebrador del "sórdido monoteísmo del mercado". (R. Garaudy). A la disección de ese alienante mecanismo de modernización capitalista, al cual han adherido con entusiasmo digno de mejor causa la totalidad de gobiernos latinoamericanos, con independencia de su signo político-ideológico, dediqué mi ensayo "El desembarco invisible" (Internet). 


\begin{abstract}
Tu libro Antihistoria Ecuatoriana (Universidad Central, Quito, 2010) ha devenido un acontecimiento en la literatura ecuatoriana. ¿Has tenido problemas políticos con el régimen del presidente Correa a causa de la sinceridad puesta en el libro? ¿Ha sido muy aguda la crítica negativa?
\end{abstract}

Con la perspectiva del quinquenio trascurrido desde su primera aparición, pienso que la principal contribución de Antihistoria... estribaría en su condición de material pionero en la develación del carácter conservador/modernizante de la autodenominada revolución ciudadana, una suerte de garcianismo del siglo XXI. Creo que los casi nueve años de "correísmo" han consolidado el Estado colonial/ moderno analizado por A. Quijano. Todo esto aderezado con la pobretología bancomundialista, una política asistencialista que confunde los efectos con las causas.

En cuanto a si Antihistoria... me ha significado represalias por parte del gobierno de Alianza País, debo comentarte que tal cosa no ha ocurrido, probablemente debido a mi status de actor político no convencional. Más allá de lo personal, sin embargo, la realidad es que Ecuador soporta una escalada represiva legal y factual de inspiración orwelliana, exacerbada después del sangriento 30/S del 2010, cuando el mandatario Correa tuvo que afrontar una asonada policial/militar originada en demandas gremialistas.

En referencia a la opinión de los lectores de Antihistoría..., te comentaría que, para alguien -como yo- que ha dedicado su vida a las actividades académicas, la mayor retribución que podía recibir -y que la he recibido- no ha sido otra que la creciente aceptación de ese aporte bibliográfico por las nuevas generaciones de colegiales y universitarios. Desde luego, me habría gustado que Antihistoria... suscitara un mayor número de trabajos de crítica académica.

\title{
¿Qué otros libros de tu autoría pondrías de relieve?
}

Me considero un autor que ha exagerado con su oficio. Creo que debí utilizar con mayor rigor y frecuencia “el hacha de Rulfo”. Más allá de esta autocrítica tardía, autorizaría la reedición de títulos como mi primigenio Teorías sobre el subdesarrollo, originalmente publicado por la editorial mexicana Diógenes, que dirigiera el recientemente fallecido Enmanuel Carballo; Las transnacionales y América Latina (UNAM, 1982); América Latina: descenso al Cuarto Mundo (Mención en un concurso que convocara la Asociación de Economistas de América Latina y el Caribe hacia 1990); Diálogos imaginarios (1994), un compendio de mis primeras reflexiones impugnadoras del todavía hegemónico paradigma de la Modernidad ; La disidencia en Disneylandia (1998), y Conversaciones con Marcos, inicialmente publicado por Eskeletra (1996) y posteriormente traducido al italiano por Roberto Bugliani y editado por Riuniti (Roma, 1997), que además lo incorporó a su colección de Clásicos Universales.

¿Qué hay detrás de este último libro? ¿Cómo y dónde fue la entrevista con el famoso Subcomandante? Preliminarmente, ese trabajo fue previsto como una aproximación al proceso histórico del país azteca, proceso al cual -en una estadía en la UNAM en los años 70- lo vislumbré muy similar en sus efectos a los que en estas latitudes andinas provocara la conquista/colonización española. A mediados de los 90, particularmente a consecuencia de la atronadora salida a escena del Ejér- 
cito Zapatista de Liberación Nacional (EZLN) en la ultradepauperada provincia de Chiapas, el 1 de enero de 1994 (el mismo día de la anexión de México a los EE. UU., con la vigencia del TLCAN), ese proyecto historiográfico me apareció incompleto, truncado, si no incluía informaciones y análisis de un suceso al que Carlos Fuentes bautizara como la "primera revolución poscomunista”. En este marco nació la idea de un coloquio imaginario con el personaje estelar de la insurrección del EZLN, el Subcomandante Marcos (actualmente resucitado bajo el nombre de Subcomandante Galeano), diálogo que terminó convirtiéndose en la tercera y última parte del libro en referencia.

Desde luego, y conforme consignara en el prólogo del citado libro, los puntos de vista del "Sup" Marcos corresponden ya a transcripciones textuales de escritos de su autoría, ya a citas de documentos oficiales de la organización rebelde. A casi dos décadas de la primera edición de Conversaciones..., me complace sobremanera haberme constituido en una suerte de médium para difundir el fuego, la verdad y la belleza de la palabra de los quijotescos sobrevivientes de la civilización maya. En cuanto a la realidad de la entrevista, alguna vez objetada, he apelado al juicio de J.L. Borges, quien, en alguna de sus impecables divagaciones, apunta que, con el paso del tiempo, las situaciones más delirantes devienen hechos tangibles.

\section{Como periodista también has tenido mucho éxito. ¿Cómo evalúas tu experiencia en ese campo?}

Se trata de un género que comencé a cultivarlo desde temprano. Me he sentido atraído por él en la medida que permite tomar el pulso de los acontecimientos en el momento en que más interesan al gran público. Si, como se ha dicho, el periodista escribe para el olvido, también es cierto que, acaso como compensación, al abordar al presente como historia viva puede contribuir en algún grado a modularla. En estos tiempos de proliferación de regímenes caudillistas y autocráticos en el continente, confieso que me resulta inadmisible el periodismo imparcial y aséptico; pero que, por acción u omisión, deviene apologético del orden establecido. Soy un convencido de que, en países como los nuestros, la objetividad y la pasión política debe constituir una amalgama indisoluble. Durante los tres últimos lustros he podido preservar mi vocación periodística especialmente como colaborador de la Agencia Latinoamericana de Información (ALAI).

\section{Tu perspectiva literaria ha salido de la economía para localizarse en la ecología. ¿A qué obedece este giro?}

Más que de un viraje se trataría de una actualización, un aggiornamento, en dirección a recuperar una visión totalizante de la evolución/involución de las relaciones entre los seres humanos y de las de estos con los ecosistemas. Me explico. La palabra economía viene de dos vocablos griegos: oikos que significa casa y nomos que equivale a administración. Únicamente que en su sentido original "casa" no era el sinónimo de la vivienda familiar -conforme a la significación que se le confiere en la actualidad- sino que tenía una connotación más amplia y compleja, similar al concepto contemporáneo de hábitat de los biólogos y ecólogos. Por otro lado, el vocablo “administración” tenía el sentido preciso del establecimiento de 
prioridades para la asignación de recursos escasos, lo cual presuponía el principio de frugalidad. En ambos sentidos sustantivos, la economía ha sido falsificada con el advenimiento de los Tiempos Modernos, fruto del Renacimiento.

La paulatina imposición de la razón instrumental -dinero y ciencia positiva (tecnología)- que ya se advirtiera en la corriente fundadora de esa disciplina en su versión moderna -el mercantilismo-, se desviará hasta el absurdo principalmente bajo la influencia de la escuela neoclásica, soporte de la actualmente hegemónica política neoliberal, una teoría/práctica funcional a los intereses del capital financiero/especulativo, actualmente principal protagonista y benificiario del despojo de las riquezas naturales de continentes y países a través de la monoproducción y el extractivismo.

Los socialismos estatalistas europeos, que colapsaron a la par de la desintegración de la URSS en 1991, y el de China, particularmente después de las reformas procapitalistas de Deng Xiao Ping en los 70, deben ser comprendidos también como tributarios de ese enfoque reduccionista, crematístico y ferozmente antropocéntrico de lo económico, fundado en la falsa premisa de la inagotabilidad de los recursos naturales, energéticos, bióticos y atmosféricos.

Expuesto de modo propositivo, la recuperación de la visión totalizante/ holística de la tradición grecolatina tiene que ser asumida como la condición sine qua non para la preservación de la vida en el planeta Tierra, tanto más en estos tiempos de mundialización del capitalismo bajo comando de las gigantes y desinhibidas corporaciones transnacionales.

\section{Con esta posición se ha alineado recientemente el papa Francisco. ¿Cuál es tu opinión sobre esa postura?}

La considero una respetable crítica a las generalizadas prácticas bárbaras del capitalismo corporativo, mas no a la esencia de ese régimen económico/social con sus correlatos alienantes. Personalmente, no creo en la posibilidad de un "capitalismo vegetariano".

\section{¿Y la paz internacional? Por favor, indícame tu punto de vista sobre la paz en el mundo, jesa utópica esperanza!}

Considero que la paz -igual que la libertad o la felicidad- comporta un concepto metahistórico; una aspiración, un horizonte siempre anhelado por los colectivos humanos, aunque nunca alcanzado a plenitud y menos a escala ecuménica. La condición metahistórica de la paz no significa, sin embargo, que tal categoría ético/ política no pueda ser terrenalizada, es decir, aproximada a coordenadas concretas de tiempo y espacio. A la luz de esta última reflexión, destacaría algunas cuestiones que no convendría soslayar en la lucha por la defensa de la paz internacional e intranacional, como las siguientes:

- Conforme al economista austriaco J.Schumpeter, la lógica íntima del orden capitalista/imperialista corresponde a la "destrucción creativa", un postulado que describe el proceso por el cual -a través de reestructuraciones demográficas y territoriales violentas, invariablemente respaldadas por actores político/ 
sociales criollos- la tecnología existente en una determinada circunscripción geográfica es reemplazada por tecnologías más productivas y rentables.

- El principio de la "destrucción creativa” constituiría la causa primigenia del terrorismo de Estado, estrategia extrema de dominación que, como corolario del 11/S del 2001, ha devenido la fórmula con la cual Washington y sus clientes político/militares buscan neutralizar a enemigos reales o potenciales de la globalización corporativa y de su fundamentalista discurso único con soporte en el mal llamado libre comercio y en la democracia formalista.

- ¿Cuáles son los sujetos sociales a destruir? A este respecto, cabe recordar que en la semiótica del Pentágono la palabra terrorista tiene una descripción muy laxa, puesto que incluye a líderes sindicales, campesinos e indígenas alzados en armas, partidos y organizaciones políticas anti-sistema, activistas de los derechos humanos, medios de comunicación independientes, intelectuales no alineados, cristianos liberacionistas, militares nacionalistas, estudiantes rebeldes, ecologistas.

- A últimas fechas, la Casa Blanca y sus mandantes han introducido una variante a la doctrina de la seguridad imperial: la cruzada contra el denominado crimen organizado transnacional. Esta reformulación habría sido mentalizada para que regímenes subsidiarios de Washington-la práctica totalidad de los gobiernos latinoamericanos, entre ellos- puedan sustentar declaratorias de guerra contra sus propios pueblos a través de expedientes como el endurecimiento de sus códigos penales, la policialización de las fuerzas armadas, la modernización del espionaje interno, la creación de guardias pretorianas y/o la represión pura y dura (que puede incluir tácticas como los "falsos positivos" tan nutridos en Colombia o los crímenes perfectos de las desapariciones tan frencuentes en el México de Felipe Calderón y Enrique Peña Nieto). Casi huelga señalar que esta guerra contra el "enemigo interno" ha sido diseñada para favorecer al lumpenizado Gran Capital: banca primermundista, principa beneficiaria del blanqueo de capitales originados en el narcotráfico; fabricantes metropolitanos de armamentos destinados a ambos bandos del conflicto; firmas proveedoras de mercenarios, etc., etc.

- Paradójicamente, semejantes expresiones de la violencia del establecimiento global, lejos de probar la fortaleza política y moral del establishment, han venido a revelar no solamente la crisis del capitalismo como régimen económico/ social, sino, también, el colapso en curso de la propia civilización del capital.

- En el ensayo titulado "Implosión del capitalismo y pensamiento alternativo latinoamericano" (ALAI, 2013), adelanté una primera disección de las causas raizales del hundimiento de la Modernidad capitalística, al tiempo que afiancé mi convicción de que entidades "primitivas" como el mexicano EZLN o la ecuatoriana CONAIE, con sus planteos de organización no-capitalista para sus respectivos países, alumbran la posibilidad de sociedades más armoniosas, más humanas.

Sept./2015 
PRESENTACIÓN LIBROS

\section{Book's Review}

TENDENCIAS

Revista de la Facultad de Ciencias Económicas y Administrativas. Universidad de Nariño

Vol. XVII. No. 1 - 1er. Semestre 2016, Enero-Junio - Página 179

\section{PRESENTACIÓN}

\section{Por: Ana María Córdoba Barahona}

Los libros y temas de matemáticas, casi siempre causan rechazo por creer que a ésta área del conocimiento solo pueden acceder algunas mentes espectaculares; ha sido uno de los errores de la educación primaria, secundaria y aún universitaria, que una gran mayoría arrastramos desde la infancia, cuando nuestros primeros maestros, quizás con la intención de que se tomen las matemáticas como algo importante en la formación intelectual y personal, asumieron una metodología recia con el que se logró el efecto contrario.

Por eso causa alegría encontrar un EI maravilloso mundo de las Matemáticas y la Economía escrito por nuestro habitual colaborador Roberto Posso Ordóñez a par-

tir de su fecunda experiencia académica en la educación superior de su país, Ecuador, que le ha permitido observar la típica actitud del estudiante que selecciona una carrera universitaria que no tenga que ver con las matemáticas. El Profesor Posso muestra en su texto una forma lúdica para acercarse a los números e integrarlo a la vida como un valor que puede contribuir a señalarnos muchos caminos. Intenta, de alguna manera, subsanar esas actitudes obsoletas de algunos profesores que nos alejaron de la maravilla de jugar con los números para aprender muchas cosas.

En El maravilloso mundo de las Matemáticas y la Economía el doctor Roberto Posso propone una serie de consejos pedagógicos que pueden mejorar mucho la presentación de investigaciones, porque todo debe estar al alcance todos, por difícil que parezca y nos ofrece elementos de juicio para lograr una interpretación de resultados clara y concisa. Debería ser un libro de consulta permanente cuando en nuestra vida académica tengamos que acudir a las cifras y conceptos.

Nos alegra haber tenido la oportunidad de leer este texto, clave en toda actividad del conocimiento y sobre todo, para que la actividad investigativa tenga sentido para la sociedad. Felicitaciones al profesor universitario Roberto Posso Ordóñez por sus preocupación por el miedo a las matemáticas de los jóvenes universitarios de cualquier parte, al menos del tipo de países como los nuestros. 


\section{EDICIÓN ANTERIOR / PREVIOUS EDITION}

\section{Vol. XV No. 2 Segundo Semestre 2015}

\section{PRESENTACIÓN}

\section{ARTICULOS DE INVESTIGACIÓN}

Luis Hernando Portillo Riascos. Universidad de Nariño, Economía. Extractivismo clásico y neoextractivismo, dos tipos de extractivismos diferentes?: análisis a partir de los casos de Ecuador y Colombia (Segunda parte)

Dummer Mamian Guzmán. Universidad de Nariño. Mocondino en su historia: la abolición de su resguardo.

Richard Iván López Zambrano. Universidad de Nariño. Evaluación de la vulnerabilidad de los jóvenes a no educarse: Una aproximación cuantitativa para el caso colombiano.

Vanesa k. Bolaños Guerreo y Daisy Triviño Jaramillo. Egresadas de Economía U. de Nariño. Evidencia de las alteraciones en la racionalidad económica causadas por el subsidio "familias en acción” en San Juan de Pasto, 2012.

Laura Marcela López Posada. Universidad del Tolima. Manifestaciones de cultura empresarial: una mirada desde la Asociatividad en las MIPYMES

Andrés Mauricio Gómez Sánchez. Universidad del Cauca. Fuga de demanda en el sector comercial de Popayán: Un análisis probabilístico.

José Javier González Millán, Miryam Teresa Rodríguez Díaz, Jenny Mairena Herrera Rodríguez - Universidad Pedagógica de Colombia - Universidad Nacional de Colombia. Practicas de responsabilidad social empresarial y gobierno corporativo en el sector bancario de la provincia de Sugamuxi en el departamento de Boyacá - Colombia.

Vanesa Campo y Ramo Sanchis. Universidad de Valencia - España. Factores clave en el éxito de las empresas agrarias. El caso de las cooperativas hortofrutícolas.

Neritza Alvarado, Maryoly Molero, Ingrid Olmo, José Soto. Universidad del Zulia - Venezuela. El papel de la nueva PDVSA en la lucha contra la pobreza y la exclusión social en Venezuela.

ARTICULOS DE REFLEXIÓN

Edwin Tarapuez Chamorro, María Dolly García González y Nélida Castellano.- Universidad del Quindío. Diseño y validación de un modelo de encuesta para medir la intención empresarial en los estudiantes universitarios de último semestre.

\section{ARTICULOS DE REVISIÓN}

Pedro A. Bohórquez Pulido y Juan Cendales Rodríguez. Universidad Nacional

Las Pymes y la política pública ambiental en Colombia: re-direccionamiento con base en la cultura organizacional

\section{VIDA UNIVERSITARIA}

Amylkar d. Acosta m. Carlos Gaviria: el librepensador

Carlos Patiño Bucheli. Alas para volar

Presentación de libros

Edición anterior

Normas para los colaboradores 


\section{NORMAS PARA LOS COLABORADORES 2016}

Guidelines for contributors

1. Todo artículo enviado a la revista debe ser original e inédito. Por tanto, cada articulista firmará previamente una Declaratoria de originalidad y cesión de derechos del trabajo escrito, formato que se hará llegar una vez se recepcione el artículo y antes de enviar el material a los evaluadores. El envío del artículo supone el compromiso por parte del autor, de no someterlo al mismo tiempo a la consideración de otras publicaciones periódicas y en la que acepta ceder los derechos de publicación y distribución.

2. La evaluación de los artículos estará a cargo de pares académicos seleccionados dentro o fuera de la Facultad y de la Universidad, de acuerdo al área de los mismos, a quienes se enviará el material sin el nombre del autor o autores. Tampoco el autor o autores conocerán el nombre del par o pares evaluadores (Sistema de doble ciego o peer review).

3. El Consejo Editorial de la revista respetará el concepto o conceptos de los evaluadores. En el evento de presentarse conceptos contrarios buscará un tercero que permita tomar una decisión.

4. El editor (a) de la Revista se reserva el derecho realizar los cambios editoriales que requieran los artículos, incluyendo los títulos de éstos, así como su devolución al autor en caso de presentar deficiencias.

5. Las palabras claves no deben ser menores a 3 ni excederse de 6

\section{EL ARTÍCULO DEBE CUMPLIR CON LOS SIGUIENTES REQUERIMIENTOS:}

- Título y palabras clave en español, inglés y portugués

- El título del artículo debe colocarse en los tres idiomas en la primera página.

- Las palabras clave van debajo del resumen en el respectivo idioma. Igualmente la clasificación JEL.

- Los nombres y apellidos del autor se ubican debajo de los tres títulos. Si los autores son más de dos se anotarán de acuerdo al orden de participación en la autoría del artículo. Estos se anotarán de forma estandarizada. Ejemplo: PEREZ RODRÍGUEZ_Mario Alberto

- La reseña bibliográfica del autor o autores se escribirán debajo del título del artículo (que ya se ha escrito en los tres idiomas) en el siguiente orden: título 
académico de mayor grado, área del conocimiento, la Universidad donde realizó dichos estudios, vinculación institucional, dirección electrónica, país, enmarcado en dos líneas. Ejemplo:

Doctor en Ingeniería Multimedia, Universidad Politécnica de Cataluña, UPC. Docente Departamento de Diseño, Universidad de Nariño. Email: cordobacely@ udenar.edu.com, Colombia.

\section{Favor NO agregar más datos.}

- Al comienzo del artículo debe incluirse un resumen (No mayor a 200 palabras) en español, inglés y portugués, donde se sinteticen los propósitos, la metodología y las conclusiones principales. Después del resumen deben ir entre 3 y 4 palabras clave y la clasificación JEL (Journal of Economic Literature), la cual se puede acceder en la siguiente dirección: http://www.aeaweb.org/journal/ jel_class_system.html

- La extensión del artículo debe ubicarse entre 15 y 25 páginas, tamaño carta, a espacio y medio, con los siguientes márgenes: izquierdo $4 \mathrm{~cm}$; derecho $3 \mathrm{~cm}$; superior 2,5 cm; inferior 2,5 cm. Fuente: Arial. Tamaño 12.

- El artículo debe ser enviado como archivo adjunto Word para Windows XP y posteriores a los correos electrónicos: revistatendencias@udenar.edu.co amacoba@udenar.edu.co y amacoba@gmail.com

- Los cuadros y gráficas de los artículos deben estar en el cuerpo de texto, con su ubicación adecuada y respectiva numeración ascendente. Adicionalmente enviarlos en un archivo de Excel como una medida de precaución para efectos de imprenta.

- El número de cuadros y gráficos debe limitarse a lo estrictamente necesario, evitando su redundancia con el texto.

- Las referencias bibliográficas se colocan al final del artículo y deben ir enumeradas. Estas deben coincidir con las citas que se hacen en el texto del artículo y no deben sobrepasar de 30 . Una más y se considera copia. Se recomienda limitar las REFERENCIAS y NOTAS a las estrictamente necesarias y escribirlas con una letra de menor tamaño que el texto. Ejemplo:

Texto: Arial 12, Referencias: Arial 10.

- Las referencias bibliográficas deben limitarse a las que han sido empleadas en el texto del artículo. Se solicita consignar con exactitud, en cada caso, toda la información necesaria (nombre del o los autores, título completo y subtítulo, cuando corresponda, editor, ciudad, mes y año de publicación, número de páginas, y si se trata de una serie, indicar el título y el número del volumen o la parte correspondiente, etc.). Las citas deben hacerse dentro del texto, utilizando solamente el encabezado de la referencia citada al final del artículo y la correspondiente página. Por ejemplo: (Sen, 2000: 118). También se puede hacer de la siguiente manera: Como señala Sen (2000: 118), “.... ... La referencia bibliográfica de la anterior cita es la siguiente: SEN, Amartya (2000). Desarrollo 
y libertad. Planeta Colombiana Editorial S.A. Santafé de Bogotá, D.C. Julio, primera reimpresión. 440p.

- Si se trata de un artículo de revista, la cita dentro del texto sería, por ejemplo: (Vaca; Díaz, 2004: 100), que correspondería a la siguiente referencia: VACA M., Orlando; DÍAZ, Fernando (2004). "Potencial impacto del libre comercio sobre la educación en Colombia”. En: Nova. Enero-diciembre, año/vol. 2, No. 002. Bogotá, Colombia. Pp. 99-102.

- Si la fuente está en Internet, el ejemplo sería: (Tapia, 2006: 700), que correspondería a la siguiente referencia: TAPIA M., Joaquín (2006). "Apertura comercial y eficiencia económica del sector agropecuario de México en el TLCAN”. En: Comercio Exterior, Vol. 56, Núm. 8, Agosto, pp. 694-702. [En línea] Disponible en: http://revistas.bancomext.gob.mx/rce/magazines/94/4/Tapia.pdf (consultado nov. 5-06).

7. Artículo que no cumpla con las presentes normas no será tenido en cuenta para su trámite posterior.

8. Si el artículo es preseleccionado por la Dirección de la revista, el (los) autor (es) deben esperar hasta que el Consejo Editorial lo seleccione. Aún si el (los) artículo (s) que lleguen a la preselección o selección, no necesariamente la publicación es inmediata. Se somete a turno.

La aplicación rigurosa de las normas expuestas asegura la calidad editorial en armonía con la periodicidad semestral. 


\section{SUSCRIPCIÓN REVISTA TENDENCIAS}

La Revista TENDENCIAS tiene como propósito divulgar los resultados de las investigaciones realizadas por profesores y estudiantes de la Facultada de Ciencias Económicas y Administrativas de la Universidad de Nariño y de otros centros de producción de conocimiento, sobre la base del pluralismo ideológico y conceptual. El contenido de los artículos es de exclusiva responsabilidad de sus autores.

Los invitamos a formar parte dentro de la lista preferencial de suscriptores para el envío permanente del ejemplar físico a partir de las próximas ediciones, para lo cual solicitamos, respetuosamente, diligenciar el formulario que se encuentra al final de esta invitación y enviarlo a los siguientes correos: revistatendencias@ udenar.edu.co_Mylemaya@hotmail.com

Además, reiteramos la invitación para que envíen artículos siguiendo nuestras normas, que las encuentra en nuestro sitio web: http://tendencias.udenar.edu.co/ donde pueden descargar el archivo Normas para los Colaboradores.

Mayores informes: amacoba@gmail.com_revistatendencias@udenar.edu.co Síganos en Facebook: Revista Tendencias.

FORMATO DE SUSCRIPCIÓN

\begin{tabular}{|l|}
\hline UNIVERSIDAD, INSTITUCIÓN UNIVERSITARIA O ENTIDAD \\
\hline NOMBRE DE LA BIBLIOTECA \\
\hline NOMBRE Y APELLIDO DEL FUNCIONARIO DE BIBLIOTECA \\
\hline DIRECCIÓN \\
\hline CIUDAD \\
\hline PAÍ́S \\
\hline TELÉFONO Y CELULAR \\
\hline E-MAIL \\
\hline DIRECCIÓN DE ENTREGA \\
\hline
\end{tabular}


El presente número de «TENDENCIAS», Revista de la Facultad de Ciencias Económicas y Administrativas de la Universidad de Nariño se terminó de imprimir en enero de 2016, en los talleres de Graficolor

San Juan de Pasto - Nariño - Colombia graficolorpasto@hotmail.com

Se imprimieron 500 ejemplares 